\title{
The Quality Cost Reduction in Hollow Glass Manufacturing by Taguchi Method
}

\author{
A. Adil and A. Moutawakil ${ }^{*}$ \\ Laboratoire de Physique Subatomique et Applications, University of Hassan II-Mohammedia- \\ Casablanca, Faculty of Sciences Ben M'Sik, B.P. 7955, Casablanca-Morocco
}

Received 27 June 2011, accepted in final revised form 25 October 2011

\begin{abstract}
This paper presents the results of an experimental investigation carried out to optimize the weight of a glass manufacturing bottle of a product called CC35 by Taguchi method of parameter design. The experiments have been designed using an L16 orthogonal array with thirteen factors and two levels each. So the effects of each control factor level on the performance characteristic are analyzed using signal-to-noise ratios, mean response data and analysis of variance (ANOVA). Hence, an experimental setting is established; and to measure the performance of the Taguchi method on the manufacturing process before and after the experiment, three tools are used. The Xbar and range charts measure the stability of the process, the capability index estimates the process ability to deliver a good product in regard to the target value and customer specifications. The quality loss function (QLF) was used to determine the reduction in quality cost due to the elimination of deviation of the quality characteristic (weight) from the target value. Experiment shows that the Taguchi method applied on the glass bottle's manufacturing process (CC35) ensures best stability and capability of the manufacturing process and reduces the weight which results in the quality cost down to $92 \%$.
\end{abstract}

Keywords: Hollow glass manufacturing; Taguchi; Quality loss function (QLF); Design of experiments; Optimization; Capability; ANOVA; Signal-to-noise ratio.

(c) 2012 JSR Publications. ISSN: 2070-0237 (Print); 2070-0245 (Online). All rights reserved.

doi:10.3329/jsr.v4i1.7900 J. Sci. Res. 4 (1), 155-172 (2012)

\section{Introduction}

Today the glass packaging manufacturers tend to create containers that are increasingly lighter in weight without sacrificing strength or performance characteristics. They continue to look for ways to strengthen glass, through new surface treatments and better designs, without sacrificing the improvements in material reduction and also reducing the total loss (manufacturing cost plus quality loss) [1]. To achieve this target, many studies have been made in order to improve the quality/cost ratio by optimizing the manufacturing process via regulation machine product with newer one [2], reduce the raw

\footnotetext{
*Corresponding author: moutawakil.abdelbarr@yahoo.fr
} 
material and energy consumption by recycling the waste of glass [3], using of the lightweight technology [4] , and optimization of the glass batch composition [5]. Aiming to achieve concurrence, the glass manufacturer uses many new tools and strategies to develop both the product and process designs.

This work treats the possibilities to exploit the experimental design in the weight optimization of a glass bottle (CC35) as an aim to reduce the deviation of this quality characteristic from the target value. The average cost of quality loss due to the variation of the weight of the glass bottle (CC35) from the target value is $0.028 €$ per unit, which represents $12.5 \%$ of the total product cost. The variability of the product weight is due to many problems in the production process in relationship with stability, capability and control factors levels of the manufacturing process [6] .

Therefore, study on the optimization of manufacturing process with concrete design to achieve adequate weight nominal target value is of considerable importance. In a concrete design, as the number of variables increases the number of experiments also increases. The traditional approach for such experimental studies is to use full factorial or fractional factorial design followed by response surface modeling. However, in the case of a full factorial design the number of experiments is numerous, and it is practically not possible to carry out the experiments in majority of situations [6, 7]. An alternative approach for optimization is to adopt Taguchi's parameter design method based on orthogonal arrays (OA), which is widely used in research and industrial applications [7, 8]. This method is economic as fewer experiments are required to obtain the optimum levels of the process parameters. Moreover, use of this method helps to make a process/product robust against environmental sources of noise, thus improving its field performance. Precisely, parameter design technique is the key step in the Taguchi method to achieve high quality of a product or component at low cost. However, the existing literature provides limited information on the optimization for the glass bottle manufacturing by using orthogonal array design. Thus the objective of the present study is to find out the optimum design for making a glass bottle of the product (CC35) with an economic cost.

The experiments were designed using an $\mathrm{L}_{16}$ standard orthogonal array considering thirteen process parameters each with two levels [7, 8]. Results derived from statistical analysis of the experimental data were presented, based on Taguchi's parameter design technique.

\section{Experimental Method}

Taguchi's parameter design method is a powerful tool for optimizing the performance characteristic of a product/process [6, 7] . The aim of a parameter design experiment is to identify and design the settings of the process parameters that optimize the chosen quality characteristic and are least sensitive to noise (uncontrollable) factors.

Our goal is to evaluate the effects of process parameters on the performance measure and the optimum combination of control factors that would optimize the weight of a glass 
bottle manufactured in the individual section machine (I.S) [3, 4, 9], which is chosen as the quality characteristic and at the same time to reduce the manufacturing quality cost.

Selection of control factors and their levels are made on the basis of the brainstorming session with a team of technicians most knowledgeable about and working with the process [8], the company manufacturing database, and literature review on the subject. Thirteen control factors are selected for the study and each of them is treated at two levels, as shown in Table 1.

Table 1. Controllable factors influencing the weight of the product.

\begin{tabular}{|c|c|c|c|c|c|}
\hline & Eacto & & Fact & evel & Docionation \\
\hline & Facto & & Minimal & Maximal & Designatur \\
\hline & & Zone 1 & $1140^{\circ} \mathrm{C}$ & $111^{\circ} \mathrm{C}$ & FTZ1 \\
\hline A & Feeder temperature & Zone 2 & $1120^{\circ} \mathrm{C}$ & $1140^{\circ} \mathrm{C}$ & FTZ2 \\
\hline & & Zone 3 & $1118^{\circ} \mathrm{C}$ & $1142^{\circ} \mathrm{C}$ & FTZ3 \\
\hline B & Refractory orifice disc & diameter of feeder & $46(\mathrm{~mm})$ & $52(\mathrm{~mm})$ & RDOF \\
\hline & Mould heating & Rougher mould & $420^{\circ} \mathrm{C}$ & $510^{\circ} \mathrm{C}$ & MHTpR \\
\hline & temperature & Finisher mould & $41^{\circ} \mathrm{C}$ & $51^{\circ} \mathrm{C}$ & MHTpF \\
\hline D & Mould ventilation & Rougher mould & $1 / 3$ cycle & $1 / 2$ cycle & MVTmR \\
\hline & & Finisher mould & 1/3 cycle & $1 / 2$ cycle & MVTmF \\
\hline & & Zone 1 & $500^{\circ} \mathrm{C}$ & $520^{\circ} \mathrm{C}$ & ATZ1 \\
\hline & & Zone 2 & $41^{\circ} \mathrm{C}$ & $42{ }^{\circ} \mathrm{C}$ & ATZ2 \\
\hline $\mathrm{E}$ & Lehr annealing & Zone 3 & $300^{\circ} \mathrm{C}$ & $320^{\circ} \mathrm{C}$ & ATZ3 \\
\hline & & Zone 4 & $180^{\circ} \mathrm{C}$ & $200^{\circ} \mathrm{C}$ & ATZ4 \\
\hline & & Zone 5 & $60^{\circ} \mathrm{C}$ & $80^{\circ} \mathrm{C}$ & ATZ5 \\
\hline
\end{tabular}

An orthogonal array (OA) is a fractional factorial design with pair wise balancing property [11]. The effects of multiple process variables on the performance characteristic can be estimated simultaneously while minimizing the number of test runs. A standard orthogonal array [8] shown in Table 2 was employed for the present investigation. This array is designated by the symbol $\mathrm{L}_{16}\left(2^{15}\right)$, is used to design experiments involving up to fifteen 2 level factors and has 16 rows and 15 columns. Each row represents a trial condition with factor levels indicated by the numbers in the row. The vertical columns correspond to the factors specified in this study.

Each factor is assigned to a column and 16 combinations of factors are available. Three columns of the orthogonal array are empty because only 13 factors are assigned to the $\mathrm{L}_{16}\left(2^{15}\right) \mathrm{OA}$. Replicating the experiment can often reduce the effects of high variability on experimental results. In this work, seven successive repetitions for each experiment were executed. In result, this array has 111 degrees of freedom $(\mathrm{DOF}=(16 \times 7)$ $-1)$. 
Table 2. Assignment of control factors to the table $\mathrm{L}_{16}\left(2^{15}\right)$ columns.

\begin{tabular}{llllc}
\hline \multicolumn{2}{c}{ Factor } & & Designation & $\begin{array}{c}\text { Column } \\
\text { assignment }\end{array}$ \\
\hline \multirow{2}{*}{ A } & Feeder temperature & Zone 1 & FTZ1 & 1 \\
& & Zone 2 & FTZ2 & 2 \\
\multirow{2}{*}{ B } & Refractory orifice disc & Zone 3 & FTZ3 & 3 \\
& Diameter of feeder & & RDOF & 4 \\
C & Mould heating temperature & Rougher mould & MHTpR & 5 \\
& & Finisher mould & MHTpF & 6 \\
D & Mould ventilation time & Rougher mould & MVTmR & 7 \\
& & Finisher mould & MVTmF & 8 \\
& & Zone 1 & ATZ1 & 9 \\
\multirow{2}{*}{ E } & Lehr annealing temperature & Zone 2 & ATZ2 & 10 \\
& & Zone 3 & ATZ3 & 11 \\
& & Zone 4 & ATZ4 & 12 \\
& & & ATZ5 & 13 \\
\hline
\end{tabular}

Table 3. The $\mathrm{L}_{16}\left(2^{15}\right)$ orthogonal array.

\begin{tabular}{cccccccccccccc}
\hline $\begin{array}{c}\text { Expt. FTZ1 } \\
\text { No. }\end{array}$ & $\begin{array}{c}\left.{ }^{\circ} \mathrm{C}\right) \\
\left({ }^{\circ} \mathrm{C}\right)\end{array}$ & $\begin{array}{c}\text { FTZ3 } \\
\left({ }^{\circ} \mathrm{C}\right)\end{array}$ & $\begin{array}{c}\text { RDOF } \\
(\mathrm{mm})\end{array}$ & $\begin{array}{c}\text { MHTpR } \\
\left({ }^{\circ} \mathrm{C}\right)\end{array}$ & $\begin{array}{c}\text { MHTpF } \\
\left({ }^{\circ} \mathrm{C}\right)\end{array}$ & $\begin{array}{c}\text { MVTmF } \\
(\mathrm{Cycle})\end{array}$ & $\begin{array}{c}\text { MVTmR } \\
(\text { Cycle })\end{array}$ & $\begin{array}{c}\text { ATZ1 } \\
\left({ }^{\circ} \mathrm{C}\right)\end{array}$ & $\begin{array}{c}\text { ATZ2 } \\
\left({ }^{\circ} \mathrm{C}\right)\end{array}$ & $\begin{array}{c}\text { ATZ3 } \\
\left({ }^{\circ} \mathrm{C}\right)\end{array}$ & $\begin{array}{c}\text { ATZ4 } \\
\left({ }^{\circ} \mathrm{C}\right)\end{array}$ & $\begin{array}{c}\text { ATZ5 } \\
\left({ }^{\circ} \mathrm{C}\right)\end{array}$ \\
\hline 1 & 1 & 1 & 1 & 1 & 1 & 1 & 1 & 1 & 1 & 1 & 1 & 1 & 1 \\
2 & 1 & 1 & 1 & 1 & 1 & 1 & 1 & 2 & 2 & 2 & 2 & 2 & 2 \\
3 & 1 & 1 & 1 & 2 & 2 & 2 & 2 & 1 & 1 & 1 & 1 & 2 & 2 \\
4 & 1 & 1 & 1 & 2 & 2 & 2 & 2 & 2 & 2 & 2 & 2 & 1 & 1 \\
5 & 1 & 2 & 2 & 1 & 1 & 2 & 2 & 1 & 1 & 2 & 2 & 1 & 1 \\
6 & 1 & 2 & 2 & 1 & 1 & 2 & 2 & 2 & 2 & 1 & 1 & 2 & 2 \\
7 & 1 & 2 & 2 & 2 & 2 & 1 & 1 & 1 & 1 & 2 & 2 & 2 & 2 \\
8 & 1 & 2 & 2 & 2 & 2 & 1 & 1 & 2 & 2 & 1 & 1 & 1 & 1 \\
9 & 2 & 1 & 2 & 1 & 2 & 1 & 2 & 1 & 2 & 1 & 2 & 1 & 2 \\
10 & 2 & 1 & 2 & 1 & 2 & 1 & 2 & 2 & 1 & 2 & 1 & 2 & 1 \\
11 & 2 & 1 & 2 & 2 & 1 & 2 & 1 & 1 & 2 & 1 & 2 & 2 & 1 \\
12 & 2 & 1 & 2 & 2 & 1 & 2 & 1 & 2 & 1 & 2 & 1 & 1 & 2 \\
13 & 2 & 2 & 1 & 1 & 2 & 2 & 1 & 1 & 2 & 2 & 1 & 1 & 2 \\
14 & 2 & 2 & 1 & 1 & 2 & 2 & 1 & 2 & 1 & 1 & 2 & 2 & 1 \\
15 & 2 & 2 & 1 & 2 & 1 & 1 & 2 & 1 & 2 & 2 & 1 & 2 & 1 \\
16 & 2 & 2 & 1 & 2 & 1 & 1 & 2 & 2 & 1 & 1 & 2 & 1 & 2 \\
\hline
\end{tabular}

\section{Taguchi method and robustness measure}

The goal of the parameter design is to design a robust product or process, which, as a result of minimizing performance variation, minimizes manufacturing and product lifetime costs. Robust design means that the performance of the product or process is insensitive to noise factors such as variation in environmental conditions, machine wear, or product to-product variation due to raw material differences [11]. In order to reduce this variation, two ways are possible $[12,13]$. The first way is to optimize, separately, the 
mean and the standard deviation. This method is not correct, because the condition to minimize the variability may be the reason to obtain an important deviation in regard to expected mean value. The second method is to improve, at the same time, the mean and the standard deviation. In this case we need an index taking in account, the both parameters.

As a solution, Taguchi has proposed to examine the variation using an appropriately chosen $\mathrm{S} / \mathrm{N}$ ratio $[7,8,11]$. Broadly speaking, the $\mathrm{S} / \mathrm{N}$ is the ratio of the mean (signal) to the standard deviation (noise), derived from the quadratic loss function. The formula used to compute the $\mathrm{S} / \mathrm{N}$ ratio depends on the objective function. Generally, three standard $\mathrm{S} / \mathrm{N}$ equations are widely used to classify the objective function as: 'larger the better', 'smaller the better', or 'nominal the best'. In the present study, weight of the glass bottle (CC35) is a 'nominal the best' type of quality characteristic since the goal is to optimize the weight value closely to the target specification. The standard $\mathrm{S} / \mathrm{N}$ ratio computing formula for this type of response is $[7,8]$ :

$$
S / N=-\frac{1}{8} \log _{10}\left(\frac{\bar{Y}}{S^{2}}\right)
$$

where $\bar{Y}$ is the mean of all measured results of the variable "weight" and $s$ is the standard deviation.

Signal-to-noise ratios are computed using Eq. (1) for each of the sixteen experimental conditions and are reported in Table 4. Since the experimental design is orthogonal, the factor effects can be separated out in terms of the $\mathrm{S} / \mathrm{N}$ ratio and in terms of the mean response. The average values of $\mathrm{S} / \mathrm{N}$ ratios of the thirteen control factors at each of the levels are shown in Fig. 1, and from which the levels corresponding to the highest $\mathrm{S} / \mathrm{N}$ ratio values are chosen for each parameter representing the optimum condition.

\section{Results and Discussion}

\subsection{Level average response analysis}

The level average response analysis is done by averaging the $\mathrm{S} / \mathrm{N}$ value at each level of each factor and represented in a graphical form. The average $\mathrm{S} / \mathrm{N}$, which is denoted as $\eta_{\mathrm{FL}}$ of each level are calculated using formula (2) and are shown in Table 4 [7, 8]:

$$
\eta_{F L}=\frac{1}{8} \sum_{\mathrm{i}=1}^{8}(\mathrm{ni})
$$

where $\eta_{\mathrm{i}}$ is $\mathrm{S} / \mathrm{N}$ of $i^{\text {th }}$ experiment involving the factor $F$ at level $L$.

For example, the computation of average $\mathrm{S} / \mathrm{N}$ for ATZ1 factor at low level (1) is:

$$
\eta_{\text {ATZ1 }}=1 / 8(47.53+47.44+42.76+45.44+48.34+50.06+57.18+50.20)=46.97
$$

The calculated results of each factor and level are presented in Table 5. 
Table 4. Results for quality characteristic and signal-to-noise ratio.

\begin{tabular}{|c|c|c|c|c|c|c|c|c|c|c|c|c|c|c|c|}
\hline \multirow[b]{2}{*}{ 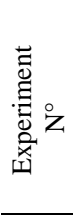 } & \multicolumn{14}{|c|}{ Factor levels } & \multirow[b]{2}{*}{$\mathrm{S} / \mathrm{N}$} \\
\hline & 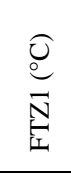 & 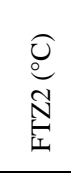 & $\underbrace{0}_{\substack{O \\
\mathcal{N}}}$ & 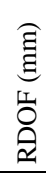 & 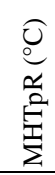 & 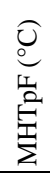 & 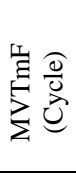 & 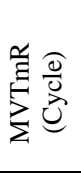 & 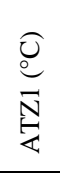 & 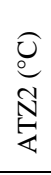 & 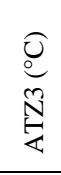 & 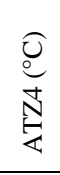 & 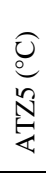 & 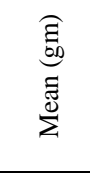 & \\
\hline 1 & 1140 & 1120 & 1118 & 46 & 420 & 41 & $1 / 2$ & $1 / 2$ & 500 & 41 & 300 & 180 & 60 & 377.80 & 47.53 \\
\hline 2 & 1140 & 1120 & 1118 & 46 & 420 & 41 & $1 / 2$ & $1 / 3$ & 520 & 42 & 320 & 200 & 80 & 358.73 & 47.44 \\
\hline 3 & 1140 & 1120 & 1118 & 52 & 510 & 51 & $1 / 3$ & $1 / 2$ & 500 & 41 & 300 & 200 & 80 & 359.46 & 42.76 \\
\hline 4 & 1140 & 1120 & 1118 & 52 & 510 & 51 & $1 / 3$ & $1 / 3$ & 520 & 42 & 320 & 180 & 60 & 353.20 & 45.44 \\
\hline 5 & 1140 & 1140 & 1142 & 46 & 420 & 51 & $1 / 3$ & $1 / 2$ & 500 & 42 & 320 & 180 & 60 & 377.36 & 48.34 \\
\hline 6 & 1140 & 1140 & 1142 & 46 & 420 & 51 & $1 / 3$ & $1 / 3$ & 520 & 41 & 300 & 200 & 80 & 351.66 & 50.06 \\
\hline 7 & 1140 & 1140 & 1142 & 52 & 510 & 41 & $1 / 2$ & $1 / 2$ & 500 & 42 & 320 & 200 & 80 & 375,05 & 57.18 \\
\hline 8 & 1140 & 1140 & 1142 & 52 & 510 & 41 & $1 / 2$ & $1 / 3$ & 520 & 41 & 300 & 180 & 60 & 358.46 & 50.20 \\
\hline 9 & 1160 & 1120 & 1142 & 46 & 510 & 41 & $1 / 3$ & $1 / 2$ & 520 & 41 & 320 & 180 & 80 & 356.21 & 38.05 \\
\hline 10 & 1160 & 1120 & 1142 & 46 & 510 & 41 & $1 / 3$ & $1 / 3$ & 500 & 42 & 300 & 200 & 60 & 375.35 & 50.87 \\
\hline 11 & 1160 & 1120 & 1142 & 52 & 420 & 51 & $1 / 2$ & $1 / 2$ & 520 & 41 & 320 & 200 & 60 & 362.05 & 39.26 \\
\hline 12 & 1160 & 1120 & 1142 & 52 & 420 & 51 & $1 / 2$ & $1 / 3$ & 500 & 42 & 300 & 180 & 80 & 376.28 & 50.01 \\
\hline 13 & 1160 & 1140 & 1118 & 46 & 510 & 51 & $1 / 2$ & $1 / 2$ & 520 & 42 & 300 & 180 & 80 & 367.16 & 52.36 \\
\hline 14 & 1160 & 1140 & 1118 & 46 & 510 & 51 & $1 / 2$ & $1 / 3$ & 500 & 41 & 320 & 200 & 60 & 351.66 & 50.06 \\
\hline 15 & 1160 & 1140 & 1118 & 52 & 420 & 41 & $1 / 3$ & $1 / 2$ & 520 & 42 & 300 & 200 & 60 & 347.07 & 46. 20 \\
\hline 16 & 1160 & 1140 & 1118 & 52 & 420 & 41 & $1 / 3$ & $1 / 3$ & 500 & 41 & 320 & 180 & 80 & 351.57 & 48.93 \\
\hline
\end{tabular}

Table 5. S/N of each controllable factor level for the quality characteristic "weight”.

\begin{tabular}{lrrcc}
\hline Factor & Level 1 & Level 2 & Level 1 - Level 2 & Optimal level \\
\hline FTZ1 & 46.97 & 48.62 & -1.65 & 2 \\
FTZ2 & 45.17 & 50.42 & -5.25 & 2 \\
FTZ3 & 47.59 & 48.00 & -0.41 & 2 \\
RDOF & 48.09 & 47.50 & 0.59 & 2 \\
MHTpR & 47.22 & 48.37 & -1.15 & 2 \\
MHTpF & 48.30 & 47.29 & 1.01 & 1 \\
MVTmF & 49.26 & 46.33 & 2.92 & 1 \\
MVTmR & 46.46 & 49.13 & -2.67 & 2 \\
ATZ1 & 49.46 & 46.13 & 3.33 & 1 \\
ATZ2 & 45.86 & 49.73 & -3.87 & 2 \\
ATZ3 & 48.75 & 46.84 & 1.91 & 1 \\
ATZ4 & 47.61 & 47.98 & -0.37 & 2 \\
ATZ5 & 47.24 & 48.35 & -1.11 & 2 \\
\hline
\end{tabular}


The difference between the average value of each factor at levels 2 and 1 indicates the relative influence of the effect. In general, when the $\mathrm{S} / \mathrm{N}$ is important, the influence of factor is important too [7]. The sign of the difference obviously indicates whether the change from level 1 to 2 increases or decreases the result. The main effects are shown visually in Fig. 1. It shows an improvement at level 1 for the following factors: RDOF, MHTpF, MVTmR, ATZ1 and ATZ3 while level 2 effects for the rest of factors decrease the quality. Hence the optimum levels for the factors based on the data are as shown in Table 6.

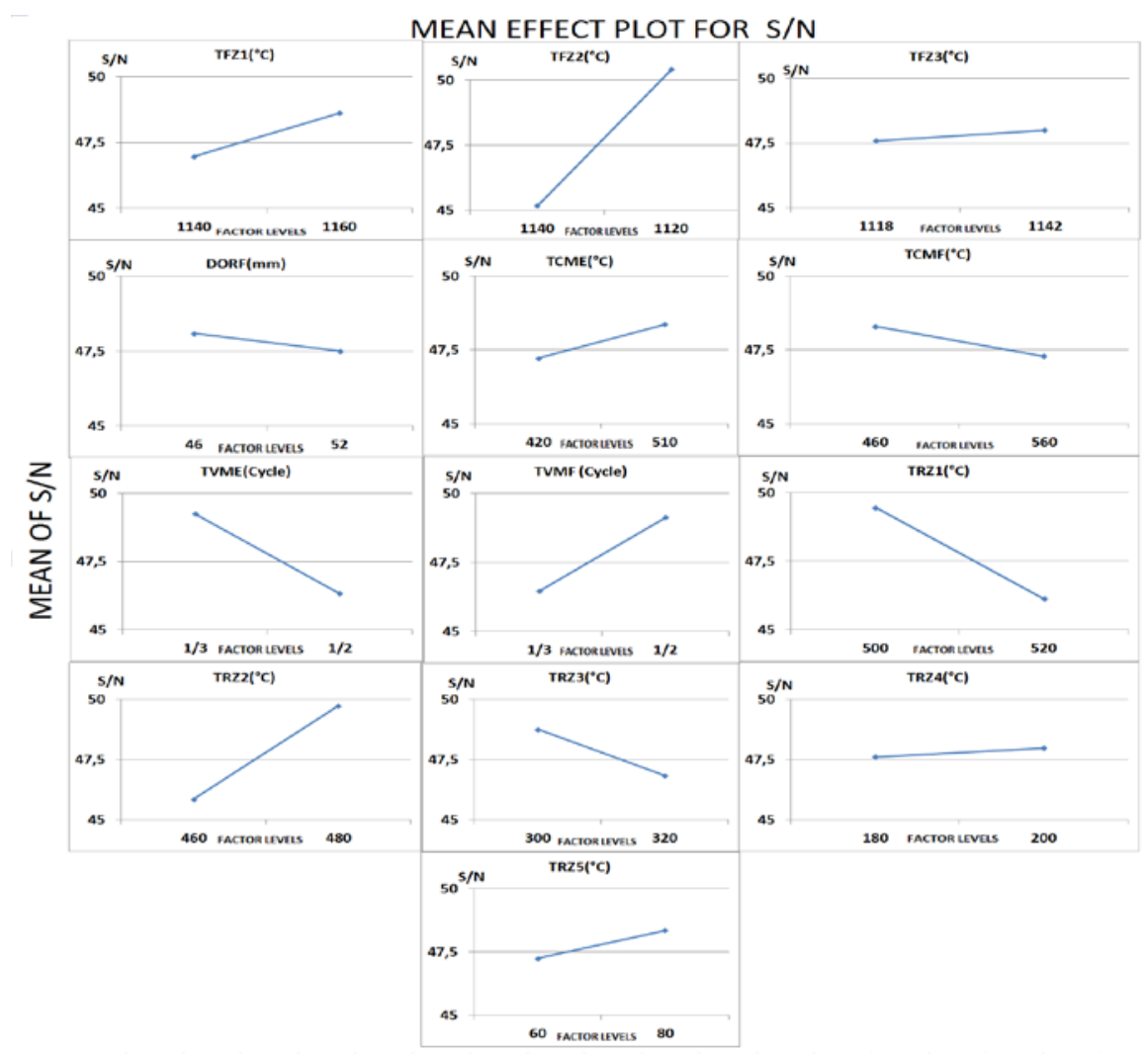

Fig. 1. Effect of control parameters vs. S/N.

Table 6. The optimum levels for the control factors.

\begin{tabular}{ccccccc}
\hline TFZ1 $\left({ }^{\circ} \mathrm{C}\right)$ & TFZ2 $\left({ }^{\circ} \mathrm{C}\right)$ & TFZ3 $\left({ }^{\circ} \mathrm{C}\right)$ & DORF $(\mathrm{mm})$ & TCME $\left({ }^{\circ} \mathrm{C}\right)$ & TCMF $\left({ }^{\circ} \mathrm{C}\right)$ & TVME $($ cycle $)$ \\
111 & 1140 & 1142 & 46 & 510 & 41 & $1 / 2$ \\
\hline TVMF (cycle) & ATZ1 $\left({ }^{\circ} \mathrm{C}\right)$ & ATZ2 $\left({ }^{\circ} \mathrm{C}\right)$ & ATZ3 $\left({ }^{\circ} \mathrm{C}\right)$ & ATZ4 $\left({ }^{\circ} \mathrm{C}\right)$ & ATZ5 $\left({ }^{\circ} \mathrm{C}\right)$ & \\
$1 / 3$ & 500 & 42 & 300 & 200 & 80 & \\
\hline
\end{tabular}




\section{Analysis of variance (ANOVA)}

The main objective of ANOVA is determination of each factor influence on results variability and its contribution to total variance of all considered factors. In this analysis, degrees of freedom, sum of squares, Fisher test etc. are calculated following ref. [8, 14]. These elements and their expressions are presented and recalled in Table. 6.

$$
S S=\sum_{i=1}^{N}\left(y_{i}-\bar{y}\right)^{2}=\sum_{i=1}^{N}\left(y_{i}^{2}-C F\right)
$$

Here $S S=$ sum of squares, $y_{\mathrm{i}}=$ value of each result, and $\bar{y}=$ mean value of results .

The correction factor CF is given by:

$$
C F=\frac{T^{2}}{N}
$$

Here $\mathrm{T}$ is the sum of all results and $\mathrm{N}$ is the total number of results. For example, to calculate the effect of a factor A on measured result, we used the formula:

$$
S S_{A}=\frac{A_{1}^{\mathrm{z}}}{N_{A_{1}}}+\frac{A_{2}^{\mathrm{z}}}{N_{A_{2}}}+\cdots+\frac{A_{\mathrm{N}}^{\mathrm{n}}}{N_{A_{N}}}-\frac{T}{N}
$$

$S S_{\mathrm{A}}$ : Sum of results $\left(y_{\mathrm{i}}\right)$ where the parameter $A$ is present, $N_{A_{\tilde{i}}}$ : Number of experiments where the parameter $A_{\mathrm{i}}$ is present.

To complete ANOVA, the following equations are required:

$$
V_{A}=\frac{S S_{A}}{f_{A}}
$$

where $V_{A}$ : variance of factor $\mathrm{A} ; f_{A}$ : degree of freedom of factor $A$.

$$
f_{A}=\frac{V_{A}}{V_{e}}
$$

where $F_{\mathrm{A}}: F$ ratio of factor $A ; V_{e}$ : variance of error.

$$
P_{A}=\frac{S s_{A}}{S s_{T}}
$$

where $P_{A}$ : influence or contribution percentage of factor A.

The degrees of freedom are an important part of statistical analysis, because of the additive information they furnish. They are defined, for Taguchi tables, as follows: 
Degree of freedom of factor $A$ : $f_{\mathrm{A}}=($ levels number of factor $A)-1$

Total degree of freedom: $f_{\mathrm{T}}=($ Experiences number $) \times$ (Repetitions number $)-1$

Degree of freedom (DoF) of variance error: $f_{\theta}=f_{T}-\sum f_{i}$, with $\mathrm{i}=A, B, \ldots$

Table 6. Summary of formulas used in ANOVA calculations of experimental results.

\begin{tabular}{|c|c|c|c|c|c|}
\hline & $\mathrm{DoF}=f$ & $\begin{array}{c}\text { Sum of squares } \\
\text { deviation }(S)\end{array}$ & $\begin{array}{c}\text { Variance } \\
(V)\end{array}$ & $F$ & $P \%$ \\
\hline A factor & $f_{A}=a-1$ & $S S_{A}=\frac{A_{1}^{2}}{N_{A_{1}}}+\frac{A_{2}^{2}}{N_{A_{2}}}-F C$ & $V_{A}=\frac{S S_{A}}{f_{A}}$ & $\frac{V_{A}}{V_{\theta}}$ & $P_{A}=\frac{\left(S S_{A}-f_{A} \times V_{B}\right)}{S S_{T}} * 100$ \\
\hline B factor & $f_{B}=b-1$ & $S S_{B}=\frac{B_{1}^{2}}{N_{B_{1}}}+\frac{B_{2}^{2}}{N_{B_{2}}}-F C$ & $V_{B}=\frac{S S_{B}}{f_{B}}$ & $\frac{V_{B}}{V_{e}}$ & $P_{B}=\frac{\left(S S_{B}-f_{A} \times V_{B}\right)}{S S_{T}} * 100$ \\
\hline Error & $f_{e}=f_{T^{-}} f_{A}-f_{B}$ & $S_{e}=S_{T}-S_{A}-S_{B}$ & $V_{e}=\frac{S S_{e}}{f_{e}}$ & & $P_{B}=\frac{\left(S_{B}-\left(f_{A}+f_{B}\right) \times V_{B}\right)}{S S_{T}} * 100$ \\
\hline Total & $f_{T}=N-1$ & $\begin{array}{r}S S_{\mathrm{T}}=(\text { Total sum of } \\
\text { square })-F C\end{array}$ & & & $\begin{array}{l}F C: \text { correction factor } \\
F C=\frac{T^{2}}{\mathrm{n}}\end{array}$ \\
\hline \multicolumn{5}{|c|}{$S S_{\mathrm{T}}=S_{\mathrm{e}}+S S_{\mathrm{A}}+S S_{\mathrm{B}}$} & $\begin{array}{l}T=\text { sum of all results } \\
n=\text { number of results }\end{array}$ \\
\hline
\end{tabular}

Table 7 shows the computed results of the ANOVA with 95\% confidence. The F-ratio and the percent contributions of the various parameters as quantified under the respective columns of Table 6 reveal that all the control factors have significant effect on the weight of the glass bottle (CC35) at the 95\% confidence level. However, the feeder temperature at the zone 2 (FTZ2) yields the most significant effect on the measured response as shown by the much higher $F$-ratio (= 379.158) and also percent contribution (32.30\%) (Fig. 2). This can be explained by the fact that in the zone 2 of the feeder, where happen a very important step of glass melting preparation called the glass homogenizing, and is finished when the properties of the glass meet the desired specifications. Perfect homogeneity exists when the glass melt exhibits no variations in the desired properties.

Variations might include local differences in refractive index, density or coefficient of expansion, all of which will affect the mechanical, physical (ex. Gob weight) and optical properties of the glass. Glass with excessive stones, cords, or seeds is also nonhomogeneous. Factors affecting homogeneity include temperature, time, batch 
composition, degree of mixing, and physicochemical relations in the glass refractory system $[3,15]$.

Table 7. ANOVA of the influential parameters for the weight of the product CC35.

\begin{tabular}{lcccccc}
\hline \multicolumn{1}{c}{ Factor } & DOF & $S$ & $V$ & $F$ & $P \%$ & $C F$ \\
\hline FTZ1 & 1 & 77.52225 & 77.52225 & 55.54723032 & 4.73 & 2113071.326 \\
FTZ2 & 1 & 529.1971612 & 529.1971612 & 379.1588474 & 32.30 & \\
FTZ3 & 1 & 9.22727041 & 9.22727041 & 6.64944944 & 0.57 & \\
RDOF & 1 & 17.181025 & 17.181025 & 12.30984993 & 1.05 & \\
MHTpR & 1 & 21.74889847 & 21.74889847 & 15.58263702 & 1.33 & \\
MHTpF & 1 & 29.44612704 & 29.44612704 & 21.09754248 & 1.20 & \\
MVTmR & 1 & 105.0039367 & 105.0039367 & 75.23315418 & 6.41 & \\
MVTmF & 1 & 119.286612 & 119.286612 & 85.84043382 & 7.31 & \\
ATZ1 & 1 & 121.619 & 121.619 & 87.16752468 & 7.43 & \\
ATZ2 & 1 & 361.9234469 & 361.9234469 & 259.3106824 & 22.09 & \\
ATZ3 & 1 & 81.314 & 81.314 & 58.29304793 & 4.97 & \\
ATZ4 & 1 & 6.076225 & 6.076225 & 4.353489845 & 0.37 & \\
ATZ5 & 1 & 21.5163449 & 21.5163449 & 15.4111718 & 1.31 & \\
ERROR & 98 & 136.7799332 & 1.39571314 & & 8.35 & \\
TOTAL & 111 & 1638.511812 & 14.76136767 & $100.00 \%$ & & \\
\hline
\end{tabular}

Tabulated $F$-ratio at $95 \%$ confidence level: $F_{0.05(1,98)}=3.9201$

Also, as shown in the Pareto graph (Fig. 2), the percentage contribution reflects the effect of every factor on final result. We can, with an error risk of $8.35 \%$, classify the control factors in 3 categories:

1. Factors with very significant effect: FTZ2, LTZ2, LTZ1, MVTmF and MVTmR; this category represents $75.54 \%$ of the total contribution,

2. Factors with medium significant effect: LTZ3, FTZ1, MHTpR, and LTZ5; represent $12.34 \%$ of the total contribution,

3. Factors with Low significant effect: MHTpF, RDOF, FTZ3 and LTZ4; represents only $3.20 \%$ of the total contribution.

We conclude that the optimization process must be focused on the five very significant factors mentioned above. 


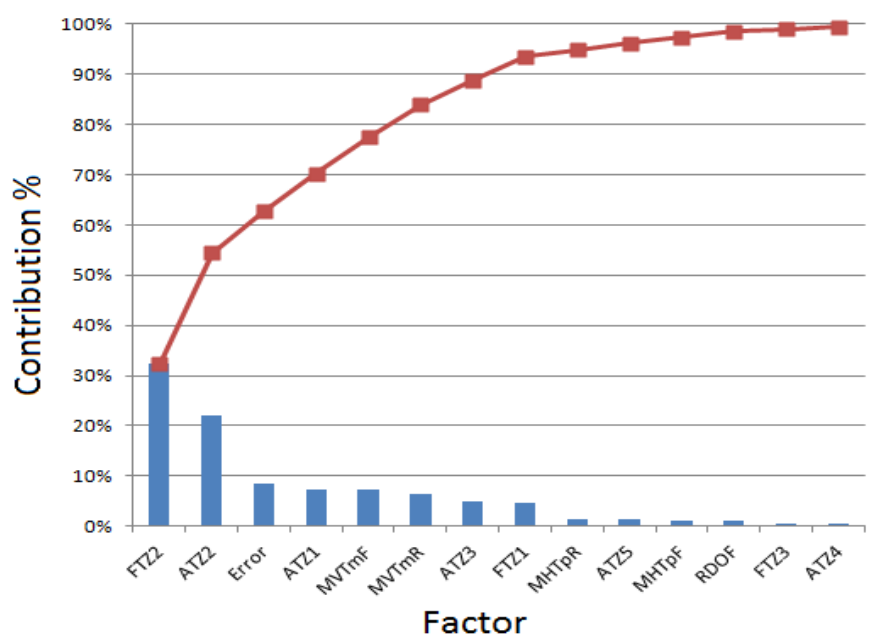

Fig. 2. Pareto classification of factors contribution.

\section{Prediction of optimum quality characteristic}

The optimum levels of the control factors are determined from the analyses of S/N ratio response, and the average values of the weight of the glass bottle (CC35) with process parameters at their respective optimal levels are calculated and shown in Table 8 [7, 8].

Table 8. The experimental optimum and the calculated response averages.

\begin{tabular}{lrc}
\hline \multicolumn{1}{c}{ Factor } & Optimal level & Calc. response average (gm) \\
\hline $\operatorname{TFZ1}\left({ }^{\circ} \mathrm{C}\right)$ & 1160 & 363.96 \\
$\operatorname{TFZ2}\left({ }^{\circ} \mathrm{C}\right)$ & 1120 & 360.00 \\
$\operatorname{TFZ3}\left({ }^{\circ} \mathrm{C}\right)$ & 1142 & 366.55 \\
$\operatorname{DORF}(\mathrm{mm})$ & 46 & 364.49 \\
$\operatorname{TCME}\left({ }^{\circ} \mathrm{C}\right)$ & 510 & 362.07 \\
$\operatorname{TCMF}\left({ }^{\circ} \mathrm{C}\right)$ & 460 & 362.53 \\
$\operatorname{TVME}(\mathrm{Cycle})$ & $1 / 3$ & 365.90 \\
$\operatorname{TVMF}(\mathrm{Cycle})$ & $1 / 2$ & 359.61 \\
$\operatorname{ATZ}\left({ }^{\circ} \mathrm{C}\right)$ & 500 & 368.06 \\
$\operatorname{ATZ2}\left({ }^{\circ} \mathrm{C}\right)$ & 480 & 366.27 \\
$\operatorname{ATZ3}\left({ }^{\circ} \mathrm{C}\right)$ & 300 & 364.15 \\
$\operatorname{ATZ3}\left({ }^{\circ} \mathrm{C}\right)$ & 200 & 360.13 \\
$\operatorname{ATZ5}\left({ }^{\circ} \mathrm{C}\right)$ & 80 & 362.01 \\
\hline
\end{tabular}


The predicted mean of the quality characteristic (weight) has been computed in the reference to the following formula:

$$
W_{\mathrm{mp}}=W+\sum(\text { calculated response average }-W)
$$

where $W$ is the grand average of performance characteristic corresponding to all the 112 $(=16 \times 7)$ experiments responses. $W_{\text {mp }}$ denotes the predicted mean of the weight of the glass bottle (CC35) at optimum conditions.

So, by application of the formula (10), the mean optimum value of the quality characteristic (weight) has been predicted as: $W_{\mathrm{mp}}=376.45 \mathrm{gm}$.

An important step in Taguchi's optimization technique is to conduct confirmation experiments for validating the predicted results. Thus a 95\% confidence interval (CI) for the predicted mean of optimum quality characteristic on a confirmation test is estimated using the following two equations $[7,8]$ :

$$
\begin{aligned}
& C I=\left(F\left(\alpha, 1, f_{\mathrm{e}}\right) \cdot \mathrm{V}_{\mathrm{e} \cdot[}\left[1 / N_{\mathrm{eff}}+1 / R\right]\right)^{0,5} \\
& N_{\text {eff }}=N /\left(1+T_{\mathrm{DOF}}\right)
\end{aligned}
$$

where, $F(\alpha, 1, f \mathrm{e})$ is the $F$-ratio required for $100(1-\alpha)$ percent confidence interval, $f_{\mathrm{e}}$ is DOF for error, Ve is the error variance, $R$ is number of replications for confirmation experiment (R=7), and $N_{\text {eff }}$ is effective number of replications. $N$ is total number of experiments [ $112(16 \times 7)]$ and $T_{\mathrm{DOF}}$ is the total degrees of freedom $111(16 \times 7-1)$ associated with the estimate of mean optimum. From Table 7 , the values are: $V e=1.395$, $f e=98$, and from standard statistical Table, the required F-ratio for $\alpha=0.05$ is: F ( 0.05 ; $98)=3.9201$. Substituting these values in Eqs. (11) and (12), the calculated confidence interval is: $C I= \pm 16.99$. Thus the $95 \%$ confidence interval of the predicted optimal weight of the glass bottle is obtained as: $(376.45 \pm 16.99)$ gm. So $359.45<W_{\mathrm{mp}}(\mathrm{gm})<393.44$.

\section{Confirmation experiment and evaluation of the impact of the Taguchi method on glass bottle manufacturing process (CC35)}

In order to test the predicted result, confirmation experiment has been conducted by running six sets of samples with a size $n=19$ at the optimal settings of the process parameters determined from the analysis (Table 9).

Table 9. Results of confirmation experiment.

\begin{tabular}{cccccccc}
\hline Sample & 1 & 2 & 3 & 4 & 5 & 6 & $\begin{array}{c}\text { Mean } \\
\text { (gm) }\end{array}$ \\
\hline $\begin{array}{c}\text { Mean weight of the } \\
\text { glass bottle (gm) }\end{array}$ & 376.11 & 376.07 & 375.99 & 375.95 & 375.94 & 376.14 & 376.03 \\
\hline
\end{tabular}


As shown in Table 9, the mean the quality characteristic (weight) obtained from the confirmation experiments is 376.03 gm, which falls within the predicted $95 \%$ confidence interval.

The optimization impact of the Taguchi method on the glass bottle manufacturing process is evaluated via the following three important elements:

\section{a. Study of the manufacturing process stability [16]}

Fig. 3 gives the X-bar and Range control charts for weights of the glass bottle (CC35) obtained during the manufacturing process of the product CC35 at optimum levels. The $\mathrm{X}$-Bar chart is sample plot of the period averages. The range chart is a sample plot of the period ranges. These charts contain control limits to aid their interpretation. All the points are within the control limits, indicating that the process is in control and is stable.
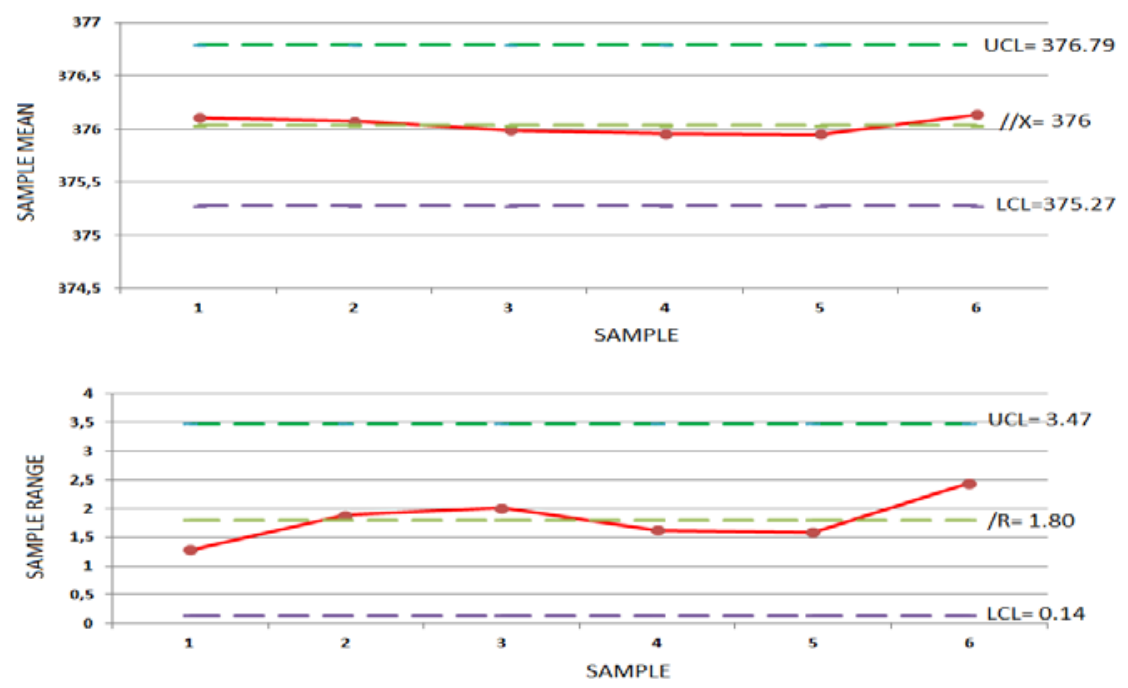

Fig. 3. X-bar/R charts for weights of the glass bottle (CC35).

\section{b. Manufacturing process capability [16]}

Fig. 4 shows the process capability of the data gathered during the glass bottle manufacturing process before (a) and after the optimization (b). It's clear that before the experimentation, the process was not close to the target with mean value of $377.07 \mathrm{gm}$ and standard deviation of 0,65 . The process capability index (Cpk) value of 0.46 is lower than the desired minimum value of 1.33 . The machine capability index (Cpm) low value of 0.31 indicates that the process is not centered and it goes beyond the upper specification limit. 
After the experimentation, and is shown in the Fig. 4 (b), the graphics indicates the glass bottle manufacturing process performed extremely well during these confirmatory trials, producing a process capability index (Cpk) of 1.52 and a standard deviation of 0.42 . The chart shows that the process mean is on the target.
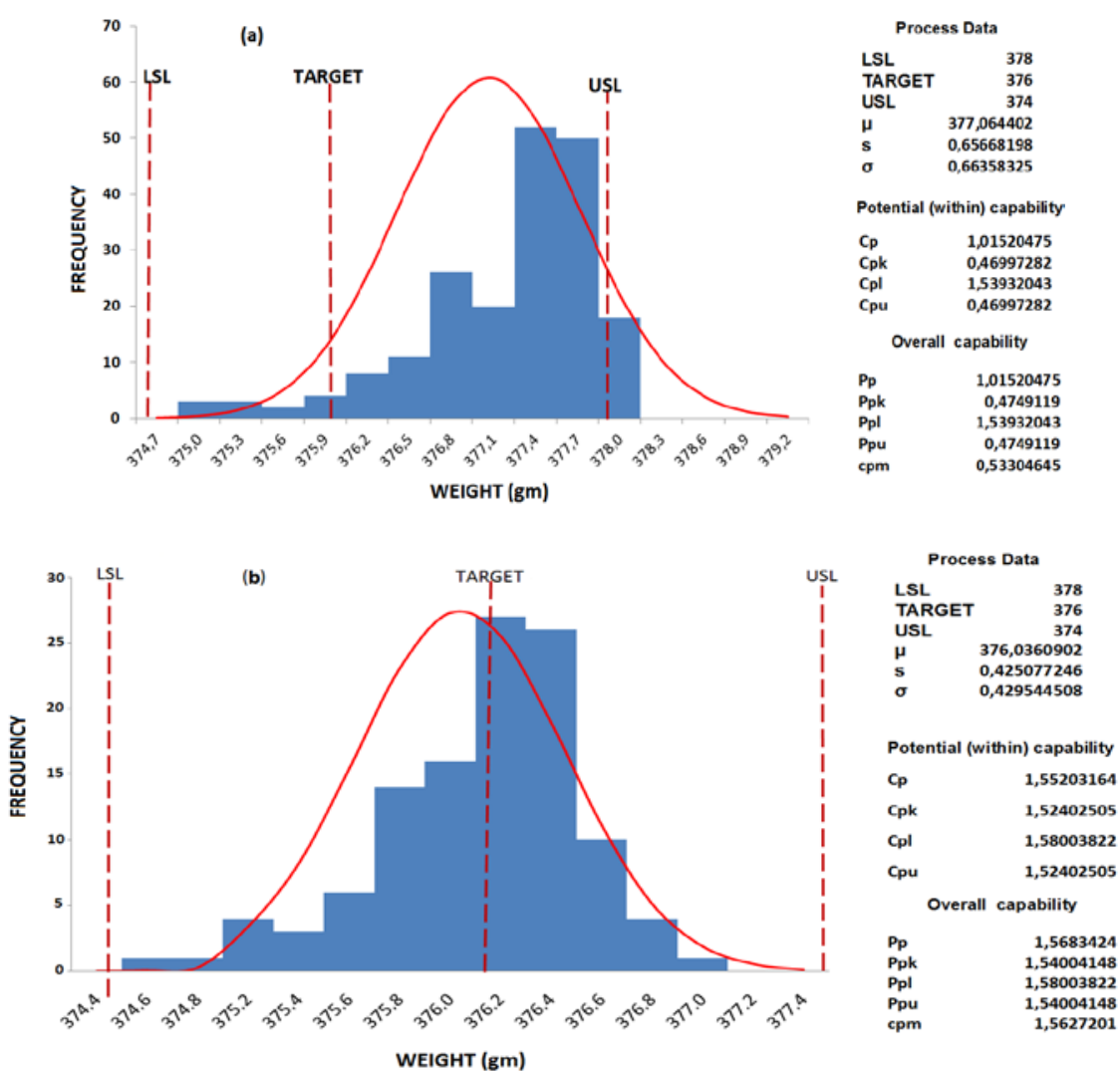

Fig. 4. Capability of manufacturing process of CC35 product, (a) before and (b) after optimization.

\section{c. Determination of the Taguchi quality loss function (QLF) and the cost of quality reduction}

According to Taguchi, the products that do not match the target do not operate as intended even if they are within the specified limits and any deviation from the target, be it within the specified limits or not, will generate financial loss to the customers, the company, and society. The loss incurred is proportional to the deviation from the target [17] .

Also, the cost of quality in relation to the deviation from the target is not linear because the customers' frustrations increase (at a faster rate) as more defects are found in a product. That is why the loss function is quadratic. 
While the total cost curve was built based on the costs of conformance and nonconformance, Taguchi's loss function is primarily based on the deviation from the quality characteristics target values [18-20] .

So with the Taguchi Loss Function, it's possible to quantify the economical losses due to the deviation of the characteristic "weight" from the target value. Following Taguchi, the formula to calculate the expected quality loss " $L$ " for a product population is given by:

$$
L=K\left(\sigma^{2}+(\mu-T)^{2}\right)
$$

where $\sigma 2$ is the variance, $\mu$ is the mean value, $T$ is the weight target value and $K$ is a constant that depends on the cost at specification limits (loss coefficient) which can be calculated by:

$$
K=\text { Cost of each unit (glass bottle (CC35)) / [(USL -LSL)/2 }]^{2}
$$

Here LSL and USL are respectively the lower and the upper specification limit.

Table 10. Calculated expected quality loss function before and after the experiment.

\begin{tabular}{ccc}
\hline & Before experiment & After experiment \\
\hline$k$ & $0.011 €$ & $0.011 €$ \\
$\sigma^{2}$ & 0.43 & 0.18 \\
$\mu$ & $377.06 \mathrm{gm}$ & $376.04 \mathrm{gm}$ \\
$T$ & $376 \mathrm{gm}$ & $376 \mathrm{gm}$ \\
$L$ & $0.028 €$ & $0.0021 €$ \\
\hline
\end{tabular}

By comparing the value of the characteristic "weight" and the expected quality loss function before and after the experiment (Table 10), we can conclude that:

a. Before the experiment, the mean value of the exceeded weight of the glass bottle from the target value was about $1.6 \mathrm{gm}$ representing a quality loss equals to $0,028 €$. According to Taguchi, this value corresponds to $100 \%$ of the estimated losses per product unit.

b. After the experiment the mean weight of the glass bottle is $\mu=376.04 \mathrm{gm}$ with a mean difference from the target value equals to $0.04 \mathrm{gm}$ and a quality loss of $0.0021 €$ per product. To estimate the percentage of the quality losses reduction Eq. (15) is used:

(Loss before experiment - loss after experiment) x 100/loss before experiment

$$
=(0.028 €-0.0021 €) \times 100 / 0.028 €=92.5 \%
$$

Therefore, the opportunity to reduce the cost of loss is about of $92.5 \%$.

Indeed, Fig. 5(a) shows that before experiment, the weight value was not close to the target value, hence a minimal loss at the target value, and an ever-increasing loss with departure either way from the target value. 
- Similarly, after experiment (Fig. 5(b)), it is clear that the weight value is roughly close to the target value, revealing that the deviation of the weight of glass bottle from the target value is minimal and consequently the quality loss function decreases.
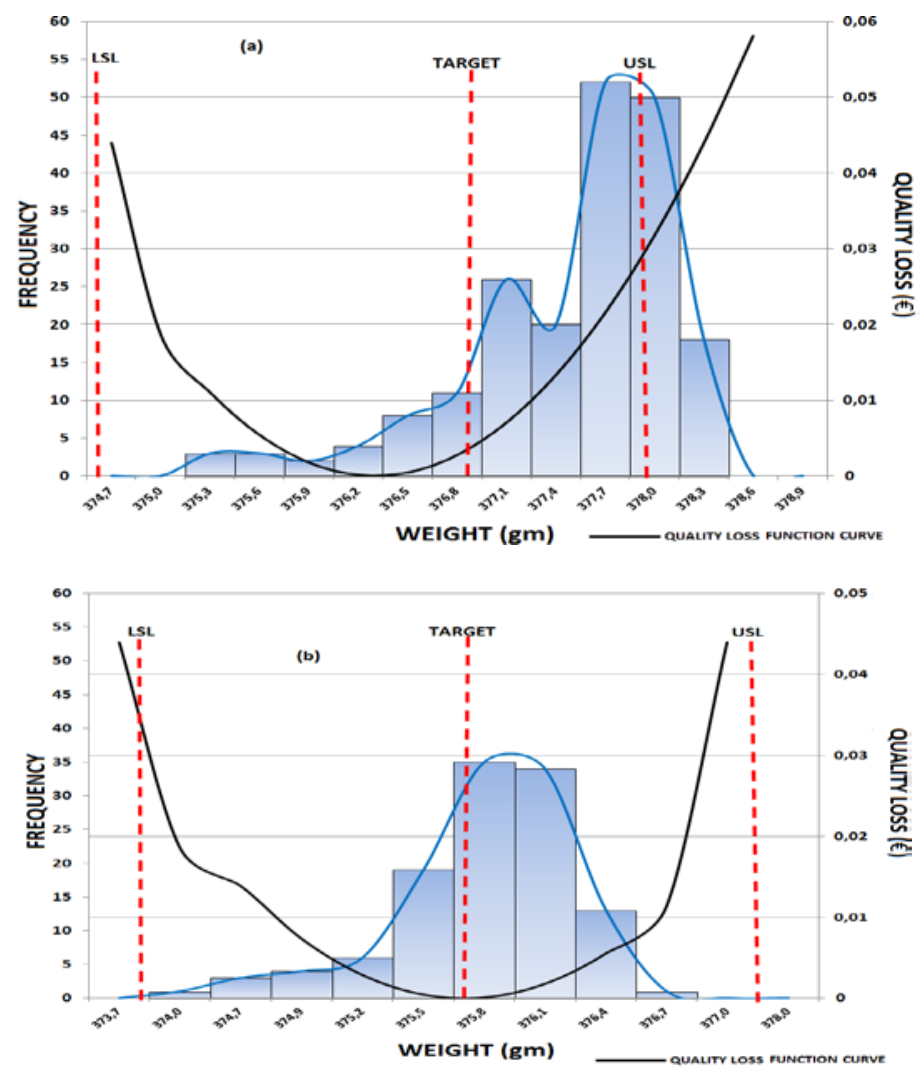

Fig. 5. Quality loss function (a) before and (b) after optimization.

\section{Conclusion}

Optimization of process parameters for weight of the glass bottle (CC35) was performed via Taguchi's parameter design method. An L16 OA was used to accommodate thirteen control factors and each with two levels for the experimental plan. Among the thirteen studied process parameters and according to the ANOVA results, the feeder temperature (Zone2) (FTZ2) and the Lehr annealing temperature (Zone1) (ATZ1) had higher significant effects on the quality characteristic "weight" of the glass bottle (CC35). Moreover, FTZ2 had the highest contribution of the order of $32.3 \%$.

The optimal levels of the process parameters were found to be: TFZ1 $\left(111^{\circ} \mathrm{C}\right)$; TFZ2 $\left.1140^{\circ} \mathrm{C}\right)$; TFZ3 $\left(1142^{\circ} \mathrm{C}\right)$; DORF $(46 \mathrm{~mm})$; TCME $\left(510^{\circ} \mathrm{C}\right)$; $\operatorname{TCMF}\left(41^{\circ} \mathrm{C}\right) ; \operatorname{TVME}(1 / 2$ 
cycle); TVMF (1/3 cycle); ATZ1 $\left(500^{\circ} \mathrm{C}\right) ; \operatorname{ATZ2}\left(42^{\circ} \mathrm{C}\right) ; \operatorname{ATZ3}\left(300^{\circ} \mathrm{C}\right)$; ATZ4 $\left(200^{\circ} \mathrm{C}\right)$; and ATZ5 $\left(80^{\circ} \mathrm{C}\right)$.

An optimized value of the weight of the glass bottle (CC35) for a 95\% confidence level was predicted as: (376.45 \pm 16.99$)$ gm; So $359.45<W m p($ gm $)<393.44$. According to confirmation experiments, the mean value of the weight of the glass bottle corresponding to the optimum conditions was obtained as 376.03 gm, which fell within the predicted range. Thus the predictions made by Taguchi's parameter design technique were in good agreement with the confirmation results. Consequently, we obtain a decrease in quality loss function (QLF) value from $0.028 €$ to $0.0021 €$ for a reduction in percentage of cost loss estimated at $92 \%$.

The results of the present investigation were valid within the specified range of the process parameters along with their chosen levels.

\section{Acknowledgment}

The authors thank the Administrator Manager of the SEVAM Company Mr. Khalid Bouchentouf and all the staff of production department for providing the facilities during the course of this experimental work.

\section{References}

1. S. H. Park, Robust design and analysis for Quality Engineering (Chapman \& Hall, London, 1996).

2. F. Al-Aina, T. Y. Zagloel, Gram Optimization using Taguchi Method of Parameter Design and Neural Network Process Model in Packaging Industry, $2^{\text {nd }}$ Asia Pacific Conference on Manufacturing System (Indonesia, 2009).

3. E. Le Bourhis, Glass: Mechanics and Technology (Wiley-VCH Verlag GmbH \& Co., 2008).

4. Environmental Overview: Complete Life Cycle Assessment of North American Container Glass, Glass Packaging Institute, Alexandria, VA 22314. http://www.gpi.org/lca/

5. G. A. Khater and M. A. Amjad, The effect of glass batch composition on the efficiency of bottle production, J. King Saud Univ. 11 Science (1) pp35-42 (Saudi Arabia, 1994)

6. D. C. Montgomery, Design and Analysis of Experiments (John Wiley \& Sons, Inc., 2005)

7. R. Roy, Design of experiments using the Taguchi approach: 16 steps to product and Process improvement, (John Wiley \& Sons Inc., 2001).

8. R. K. Roy, A Primer on the Taguchi Method, $2^{\text {nd }}$ edition (Society of Manufacturing Engineers, 2010).

9. E. A. Fenton, I. S. Glass forming machine (US Patent, 2004).

10. M. Kesuma, Analysis of Variance for Attribute Data in Taguchi‘s Approach, Proceeding of the 2nd IMT-GT Regional Conference on Mathematics, Statistics and Applications (University Sains Malysia, Penang, 2006)

11. Byrne, M. Diane, and S. Taguchi, The Taguchi Approach to Parameter Design. (ASQC Quality Congress Transaction, 1986) p 168.

12. R. N. Kackar, J. Quality Technol. 17, 176 (1985).

13. S. Takeshita and T. Hosokawa, FUJITSU Sci. Tech. J. 43 (1), 105 (2007).

14. M. G. Bala, M. Biswanath, and G. Sukamal, J. Sci. Indus. Res. 68, 686 (2009).

15. U. S. Department of Energy, Glass : industry of the future Energy and Environmental Profile of the U.S. Glass Industry (USA, April 2002).

16. M. J. Chandra, Statistical Quality Control (CRC Press LLC, 2001). 


\section{The Quality Cost Reduction}

http://dx.doi.org/10.1201/9781420038675

17. B. Lawton, I. Bass, Lean Six Sigma Using Sigma XL and Minitab (McGraw-Hill, New York, 2009).

18. N. K. Sharma, E. A. Cudney, K. M. Ragsdell, and K. Paryani, J. Indus. Systems Engg. 1 (3), 218 (2007).

19. H. M. Lee, M. Sarahintu, S. Salleh, and B.Sanugi, Taguchi's Quality Loss Function Approach in analyzing performance of the Dynamic Source Routing Protocol, Proceedings of the 5th Asian Mathematical Conference (22-26 June 2009, Kuala Lumpur, Malaysia).

20. M. Demetrescu, A. Paris and C. Târcolea, Uni-and multivariate loss functions and the Taguchi theory, BSG Proceedings 17. The International Conference "Differential Geometry-Dynamical Systems (Bucharest, Romania, October 8-11, 2009). 